\title{
Meeting the Kyoto targets: the importance of developing country participation
}

\author{
ZhongXiang Zhang ${ }^{1}$ \\ Faculty of Law and Faculty of Economics \\ University of Groningen \\ P.O. Box 716 \\ 9700 AS Groningen \\ The Netherlands \\ Tel: +31503636882 \\ Fax: +31503637101 \\ Email: Z.X.Zhang@Rechten.RUG.NL \\ Web: http://www.eco.rug.nl/medewerk/zhang/
}

\footnotetext{
1 ZhongXiang Zhang is jointly appointed as a senior fellow at the Faculty of Law and Faculty of Economics, University of Groningen, The Netherlands. He also holds a part-time professor of economics both at Chinese Academy of Social Sciences and at Peking University, Beijing. He has served as an expert/consultant to many national and international organizations. Currently, he is serving on editoral board of the five international journals and one Chinese journal.
} 


\begin{abstract}
This paper investigates the implications of progressively broadening the scope of the market of tradable permits from no emissions trading to full global trading. We start with the no emissions trading case where each Annex I country must individually meet its Kyoto targets. Next, we consider a case where trading of emissions permits is limited to Annex I countries only. We then expand the scope of the market to include all the non-Annex I countries but China. Finally, to investigate the role China plays in bringing down Annex I countries' compliance costs, we further broaden the market to include China into full global trading. Our results clearly demonstrate that the gain of the OECD as a whole increases as the market expands. Our results also show that developing countries themselves benefit from such an expansion too because it not only provides them for additional financial resources, but also helps to cut their baseline carbon emissions by a big margin. By contrast, the former Soviet Union tends to become worse off as the market expands. The potential conflict of interest between the former Soviet Union and developing countries underlines the importance of establishing clear rules of procedure about admitting new entrants before emissions trading begins.
\end{abstract}

Keywords: Emissions trading; Clean development mechanism; Greenhouse gases; Marginal abatement costs; Price of permits

JEL no. Q28, Q25, Q48, Q43 


\section{Introduction}

The Kyoto Protocol to the United Nations Framework Convention on Climate Change (UNFCCC) commits Annex I countries ${ }^{2}$ to reduce their emissions of six greenhouse gases (GHG) by 5.2\% below 1990 levels over the commitment period 2008-2012, with the European Union (EU), the United States and Japan required to reduce their emissions of such gases by $8 \%, 7 \%$ and $6 \%$ respectively (UNFCCC, 1997). The Protocol also incorporates emissions trading, joint implementation and the clean development mechanism (CDM) to help Annex I countries to meet their Kyoto targets at a lower overall cost.

However, to what extent their compliance costs can be lowered depends on the extent to which the flexibility mechanisms will be allowed to contribute to meet the Kyoto targets. Assuming that trading of emissions permits would take place globally among all the countries, Zhang (2000) analyses the implications of imposing restrictions on imports and exports of permits for both Annex I countries' compliance costs and gains of non-Annex I countries (i.e., developing countries). While that study sheds light on the contributions of abatement actions at home and abroad to meeting Annex I countries' Kyoto targets, it neglects a very important aspect. That is the scope of the market of tradable permits and its implications. This paper aims to fill this gap by investigating the implications of progressively broadening the scope of the market of tradable permits from no emissions trading to full global trading. We start with the no emissions trading case where each Annex I country must individually meet its Kyoto targets without any trading of permits across countries. Next, we consider a case where trading of emissions permits is limited to Annex I countries only. We then expand the scope of the market to include all the non-Annex I countries but China. Finally, to investigate the role China plays in bringing down Annex I countries' compliance costs, we further broaden the market to include China into full global trading. To our knowledge, this is the first study to disentangle the impacts of China on Annex I countries' compliance costs from those resulting from the rest of the world by examining the markets with and without the inclusion of China. Thus, the study provides a valuable addition to Zhang (2000). 


\section{The economic effects of progressively broadening the scope of the market}

As Zhang (2000), this study also takes the year 2010 as representative of the first commitment period 2008-2012, and derives emissions reductions required of Annex I countries from the national communications from 35 Annex I countries to the UNFCCC. In this section, we will examine the economic effects of progressively broadening the scope of the market from no emissions trading to full global trading both on Annex I countries and on non-Annex I countries, using a model based on the marginal abatement costs of 12 regions. ${ }^{3}$ The twelve regions considered are given in Table 1. The first six regions are Annex I regions, whereas the other six are non-Annex I regions whose emissions are unconstrained under the Kyoto Protocol.

Table 1

Definitions of countries and regions

\begin{tabular}{ll}
\hline Annex I countries and regions & Non-Annex I countries and regions \\
\hline 1. United States & 7. Energy Exporting Countries \\
2. Japan & 8. China \\
3. European Union & 9. India \\
4. Other OECD Countries & 10. Dynamic Asian Economies \\
5. Eastern Europe & 11. Brazil \\
6. Former Soviet Union & 12. Rest of the World \\
\hline
\end{tabular}

Using the model, we will examine the following four scenarios, which are each described in ascending scope of the market.

- No trading scenario: Each Annex I country must individually meet its Kyoto targets without any trading of permits across countries;

- Annex I trading scenario: Trading of emissions permits is allowed to take place among Annex I countries only;

- Trading without China scenario: Trading of emissions permits is expanded to include all the non-Annex I countries but China;

\footnotetext{
${ }^{2}$ Annex I countries refer to the OECD countries and countries with economies in transition. These countries have committed themselves to greenhouse gas emissions targets.
} 
- Full global trading scenario: Trading of emissions permits is further broadened to include China.

In the last two scenarios, non-Annex I countries are not required to constrain their emissions. They are allocated permits equal to their projected baseline emissions, so they only reduce their emissions by an amount equal to the number of permits they wish to sell. This means of obtaining low-cost abatement options from non-Annex I countries will further increase Annex I countries' potential for efficiency gains relative to the Annex I trading case.

\subsection{No emissions trading}

In the absence of emissions trading, the autarkic marginal abatement cost is highest in Japan, where it requires US\$ 311.8 per ton of carbon to comply with its Kyoto target in 2010 (see Table 2), and lowest in the Former Soviet Union whose autarkic marginal abatement cost is zero because it has been allocated more than needed. The above results are in line with findings from other studies (e.g., Ellerman and Decaux, 1998; MacCracken et al., 1999). By contrast, our estimate of the autarkic marginal abatement cost in the EU is very low in comparison with those estimates from Ellerman and Decaux (1998) and MacCracken et al. (1999). This is mainly because the official projections of baseline GHG emissions in 2010 by most EU member countries are very close to their targets. ${ }^{4}$ Thus, the EU only needs to take very little abatement actions to meet its targets. This leads to a very low marginal abatement cost in the EU.

\section{Table 2}

Autarkic marginal abatement costs in the no trading case, and domestic prices and the international price of permits in 2010 under the three trading scenarios (at 1998 US\$ per ton of carbon)

\begin{tabular}{lcccccc}
\hline Scenarios & $\begin{array}{c}\text { United } \\
\text { States }\end{array}$ & Japan & $\begin{array}{c}\text { European } \\
\text { Union }\end{array}$ & $\begin{array}{c}\text { Other } \\
\text { OECD }\end{array}$ & $\begin{array}{c}\text { Eastern } \\
\text { Europe }\end{array}$ & $\begin{array}{c}\text { International } \\
\text { price }\end{array}$ \\
\hline No emissions trading & 160.1 & 311.8 & 9.1 & 33.4 & 4.5 & - \\
Annex I trading & 40.7 & 40.7 & 40.7 & 40.7 & 40.7 & 40.7 \\
Trading without China & 18.6 & 18.6 & 18.6 & 18.6 & 18.6 & 18.6 \\
Full global trading & 9.6 & 9.6 & 9.6 & 9.6 & 9.6 & 9.6 \\
\hline
\end{tabular}

\footnotetext{
${ }^{3}$ See Zhang (1999, 2000) for a detailed description of the model and other applications of the model.

${ }^{4}$ The low EU baseline projections are attributable in large part to internal burden sharing of the Kyoto commitments among the member countries, having incorporated the impacts of energy policies that are currently being either implemented or negotiated in response to climate change, and to the choice of base year. See Zhang $(1999,2000)$ for detailed discussion.
} 


\subsection{Widening the scope of the market: from Annex I countries only to full global trading}

When trading of emissions permits is allowed across Annex I countries freely, the marginal cost of domestic abatement for each Annex I region equalizes. The resulting market price of permits, which is endogenously determined, is equal to 40.7 per ton of carbon (see Table 2). It is well below the autarkic marginal abatement costs for Japan and the US, but above those for the EU, other OECD countries and the Eastern Europe. Consequently, Japan and the US are importers of permits, whereas other Annex I regions are exporters of permits. Every region achieves some gains through trading, but the magnitude of the gains from trading differs substantially among Annex I countries. Given that Japan and the US have the highest autarkic marginal abatement costs, these two countries will meet $81.2 \%$ and $53.6 \%$ of their emissions reductions required in 2010 by purchasing permits, respectively (see Table 3). As a result, the total abatement costs of Japan and the US are cut by $73.0 \%$ and $49.6 \%$ under the Annex I trading scenario in comparison with the no trading case (see Table 4). In the mean time, because the market price of permits is well above the autarkic marginal abatement cost in the EU, it can benefit greatly from taking otherwise very little domestic actions in the no trading case and generating more permits for sale. As indicated in Table 3, by almost doubling domestic actions in the no trading case, the EU gains substantially (790.9\%) in the Annex I trading case.

Table 3

The share of domestic abatement actions in $2010(\%)$

\begin{tabular}{lccc}
\hline & Annex I trading & $\begin{array}{c}\text { Trading without } \\
\text { China }\end{array}$ & Full global trading \\
\hline US & 46.4 & 28.9 & 18.9 \\
Japan & 18.8 & 9.1 & 4.8 \\
EU & 196.0 & 116.0 & 71.4 \\
Other OECD & 109.3 & 77.6 & 59.0 \\
Eastern Europe & 201.6 & 132.9 & 92.4 \\
Annex I total & 65.7 & 41.5 & 27.7 \\
\hline
\end{tabular}

When trading is enlarged to include non-Annex I countries but China, more low-cost abatement options become available. Consequently, the market price of permits is pushed down to 18.6 per ton of carbon. As a result, a distinction between the international price and the autarkic marginal abatement costs 
of buying countries like Japan and the US becomes larger. Thus, these two countries can benefit from the expansion of the market by avoiding their undertaking of more costly domestic abatement actions by purchasing even more permits abroad. Their gains from trading, namely, the reductions in abatement costs relative to the no emissions trading case, rise to $87.0 \%$ and $73.3 \%$ under the trading without China scenario, respectively. When trading of emissions permits is further broadened to include China, even more low-cost abatement options from China are included. This increased supply will further push the market price of permits down to 9.6 per ton of carbon. As would be expected, the gains of Japan and the US from trading further rise to $93.1 \%$ and $85.2 \%$ under the full global trading scenario, respectively.

Table 4

The gains in 2010 under the three trading scenarios $(\%)^{\mathrm{a}}$

\begin{tabular}{lcccccc}
\hline Scenarios & $\begin{array}{c}\text { United } \\
\text { States }\end{array}$ & Japan & $\begin{array}{c}\text { European } \\
\text { Union }\end{array}$ & $\begin{array}{c}\text { Other } \\
\text { OECD }\end{array}$ & OECD & $\begin{array}{c}\text { Former } \\
\text { Soviet Union }\end{array}$ \\
\hline Annex I trading & 49.6 & 73.0 & 790.9 & 3.6 & 57.8 & 563.0 \\
Trading without China & 73.3 & 87.0 & 84.0 & 16.3 & 76.2 & 217.7 \\
Full global trading & 85.2 & 93.1 & 0.2 & 45.3 & 86.5 & 100.0 \\
\hline
\end{tabular}

a The gains are measured relative to the total abatement costs in the absence of trading for the OECD countries or the total benefits under the full global trading scenario for the former Soviet Union.

By contrast, the international price of permits becomes close to the autarkic marginal abatement cost in the EU when trading is enlarged to include non-Annex I countries but China. This will reduce the incentive for the EU to abate domestically in order to generate more permits for sale. Thus, its gain reduces substantially in comparison with the no trading case. Further expansion to include China will push the international price of permits ever closer to its autarkic marginal abatement cost. Thus, the EU is expected to experience a very small gain from such an expansion.

Because the emissions reductions required of the US and Japan to meet their Kyoto targets are about 18 times that of the EU, the two countries have much more influence on the overall gain of the OECD than the EU does. Because the gains of the US and Japan increase as the market expands, the gain of the OECD as a whole also increases. As shown in Table 4, the expansion of abatement options increases the OECD's gain from $57.8 \%$ under the Annex I trading only scenario to $76.2 \%$ under the trading without China scenario 
and to $86.5 \%$ under the full global trading scenario. The gain of $10 \%$ more with China than without China underlines the importance of the inclusion of China.

As far as the former Soviet Union is concerned, its gain tends to decrease as the market expands. The former Soviet Union is expected to experience the highest gain when trading is limited to Annex I countries only. If trading of emissions permits were broadened to include non-Annex I countries but China, its gain would be reduced by about $61 \%$ (see Table 4 ) in comparison with that in the Annex I trading only case. Its gains would further drop to $17.8 \%$ of that in the case of Annex I trading only, if trading of emissions permits were further broadened to include China. This is mainly because the inclusion of low-cost abatement options form China and other non-Annex I countries on the supply side reduces the market price received for its sold permits from US\$ 40.7 per ton of carbon under the Annex I trading scenario to US\$ 18.6 under the trading without China scenario and to US\$ 9.6 under the full global trading scenario.

\subsection{Effects on the CDM market and China}

As shown in Table 5, the supply of certified CDM credits in 2010 is estimated to be higher under the full global trading scenario than under the trading without China scenario. But, the value of the CDM market, which is derived from multiplying the endogenously-determined, international price of permits by the supply of certified CDM credits from each non-Annex I country and summing over all the corresponding products, is lower in the former case than in the latter case. This is mainly because the inclusion of China makes more low-cost abatement options available, but in the meantime cuts the market price of permits in half. Because the reduction in the price of permits is much more than the increase in the supply of CDM credits when trading is broadened to include China, the product of the price and the supply tends to be lower under the full global trading scenario than under the trading without China scenario.

With respect to the geographical distribution of the CDM flows, because of a great deal of low-cost abatement opportunities available in the energy sector of China and its sheer size of population, China is expected to emerge as the dominant host country of CDM projects. This is confirmed in Table 5, which shows that about $60 \%$ of the total CDM flows go to China. This share is broadly in line with those from other studies examined in Table 6. If China were not included, the CDM flows to other countries would at 
least double in comparison with the case where China were included, with India emerging as the dominant host country of CDM projects.

Table 5

The size and value of the CDM market and the geographical distribution in 2010

\begin{tabular}{lcc}
\hline & Trading without China & Full global trading \\
\hline Size of the CDM market (MtC) & 185.7 & 292.1 \\
Value of the CDM market (million US\$) & 3455.7 & 2795.6 \\
of which: & & \\
China & $0.0 \%$ & $60.28 \%$ \\
India & $36.83 \%$ & $15.08 \%$ \\
Energy Exporting Countries & $16.63 \%$ & $6.07 \%$ \\
Dynamic Asian Economies & $13.49 \%$ & $4.91 \%$ \\
Brazil & $0.72 \%$ & $0.25 \%$ \\
Rest of the World & $32.33 \%$ & $13.41 \%$ \\
\hline
\end{tabular}

Table 6

A comparison of the size of the CDM market and the share of China in 2010

\begin{tabular}{|c|c|c|c|c|c|}
\hline & \multirow{2}{*}{$\begin{array}{l}\text { Size of the } \\
\text { CDM market } \\
(\mathrm{MtC})\end{array}$} & \multirow{2}{*}{$\begin{array}{l}\text { Total emissions } \\
\text { reductions required of } \\
\text { Annex I countries } \\
(\mathrm{MtC})\end{array}$} & \multirow{2}{*}{$\begin{array}{l}\text { Contribution } \\
\text { of the CDM }\end{array}$} & \multicolumn{2}{|c|}{ Certified CDM credits } \\
\hline & & & & $\begin{array}{l}\text { From China } \\
(\mathrm{MtC})\end{array}$ & $\begin{array}{l}\text { Share of } \\
\text { China }\end{array}$ \\
\hline EPPA & 723 & 1312 & $55 \%$ & 437 & $60 \%$ \\
\hline G-Cubed & 495 & 1102 & $45 \%$ & 300 & $61 \%$ \\
\hline GREEN & 397 & 1298 & $31 \%$ & 228 & $57 \%$ \\
\hline SGM & 454 & 1053 & $43 \%$ & 341 & $75 \%$ \\
\hline Our projection & 292 & 621 & $47 \%$ & 176 & $60 \%$ \\
\hline
\end{tabular}

Sources: Ellerman and Decaux (1998); MacCracken et al. (1999); McKibbin et al. (1999); Van der Mensbrugghe (1998); Own calculations.

It should be pointed out that the inclusion of China is beneficial not only to Annex I countries because it increases potential of their efficiency gains, but also to China. Table 7 gives estimates of baseline $\mathrm{CO}_{2}$ emissions in China up to the year 2020 from a variety of economic modelling studies. Although estimates of the magnitude of increase in emissions differ among the studies examined, there is a consensus that $\mathrm{CO}_{2}$ emissions in China are expected to at least double over the period 1990-2010. On the current trends, China is expected to surprise the US to become the world's largest $\mathrm{CO}_{2}$ emitter by 2020 (see Figure 1). Thus, getting China involved in combating global climate change is an issue of perennial concern at the international climate change negotiations. If trading of emissions permits were broadened to include China, it would not 
only provide the country for additional financial resources, but also help to bring down its $\mathrm{CO}_{2}$ emissions by 176-437 MtC. Expressed as a percentage of its baseline emissions, this amount of emissions reductions amounts to $11.1-40.1 \%$. In addition to the reductions in $\mathrm{CO}_{2}$ emissions, it will also contribute to the reductions in local pollutants and thus will be beneficial to a more sustainable development of the Chinese economy.

Figure 1

$\mathrm{CO}_{2}$ emissions in China and the United States, 1990-2020

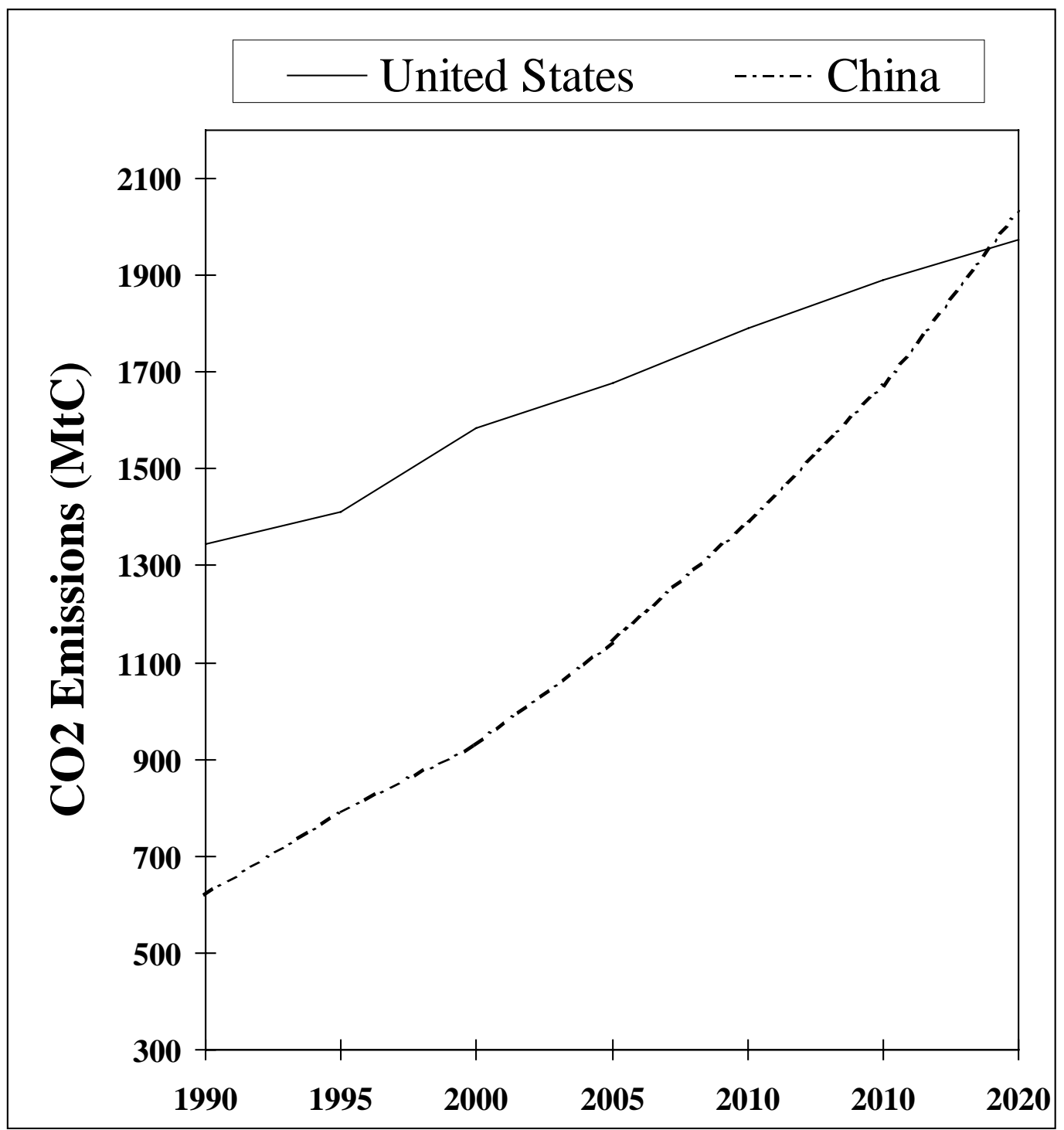

Source: Drawn based on data from EIA (1999). 
Table 7

Carbon emissions in China (MtC), 1990-2020

\begin{tabular}{|l|c|c|c|c|}
\hline Sources & 1990 & 2000 & 2010 & 2020 \\
\hline ADB (1998) & 567 & 915 & 1320 & 1695 \\
CASS (2000) & n.a. ${ }^{\mathrm{a}}$ & 841 & 1090 & 1330 \\
EIA (1999) & 620 & 930 & 1586 & 2031 \\
IEA (1998) & 657 & n.a. ${ }^{\mathrm{a}}$ & 1450 & 1929 \\
World Bank (1994) & 650 & 987 & 1512 & 2045 \\
Zhang (1997) & 587 & 899 & 1441 & n.a. $^{\mathrm{a}}$ \\
\hline
\end{tabular}

${ }^{\mathrm{a}}$ n.a. $=$ not available

\section{Summary and conclusions}

This paper has investigated the implications of progressively broadening the scope of the market of tradable permits from no emissions trading to full global trading. Our results show that if each Annex I country were required to individually meet its Kyoto targets without any trading of permits across countries, Japan and the US would face much higher compliance costs than the EU. For this reason, trading would lower their costs substantially. Moreover, the gains of these two countries increase by very big margins as the market expands from Annex I trading only to full global trading. In the mean time, the EU benefits greatly in the Annex I trading case from taking otherwise very little domestic actions in the no trading case and generating more permits for sale. But, as the market expands to include China and other non-Annex I countries, the gain of the EU reduces because the international price of permits becomes closer to its autarkic marginal abatement cost. However, because the US and Japan have much more influence on the overall gain of the OECD than the EU does, the gain of the OECD as a whole increases as the market expands.

While the OECD countries enjoy the gains from the inclusion of developing countries, the expansion of the market is beneficial to developing countries too. If trading of emissions permits were broadened to include China, the OECD would gain $10 \%$ more than without the inclusion of China. In the mean time, such an expansion would not only provide the country for additional financial resources, but also help to bring down its baseline $\mathrm{CO}_{2}$ emissions by a big margin. 
By contrast, the gain of the former Soviet Union tends to decrease as the market expands. This is mainly because the inclusion of low-cost abatement options form China and other non-Annex I countries on the supply side depresses the market price received for its sold permits. The potential conflict of interest between the former Soviet Union and non-Annex I countries may have influence on future expanding trading to non-Annex I countries, thus underlining the importance of establishing clear rules of procedure about admitting new entrants before emissions trading begins (Zhang, 1998).

\section{Acknowledgements}

This paper formed part of the presentations at the Asian Development Bank/United Nations Environment Programme's Workshop for Policymakers on the Institutional Design of the Kyoto Protocol Cooperative Implementation Mechanisms, Bangkok, 12-14 October 1999; the International Workshop on Enhancing GHG Mitigation through International Cooperative Mechanisms in Asia, Kanagawa, Japan, 26-27 January 2000; China - US Workshop on Economic and Environmental Modeling, Beijing, 5-6 March 2000; the $3^{\text {rd }}$ Biennial Conference of the European Society for Ecological Economics, Vienna, 3-6 May 2000; the 10th Annual Conference of the European Association of Environmental and Resource Economists, Crete, Greece, 30 June - 2 July 2000; the Joint Meeting of the Energy Modeling Forum and the International Energy Workshop, Stanford University, 20-22 June 2000; and at the $40^{\text {th }}$ Congress of the European Regional Science Association, Barcelona, 29 August - 1 September; as well as at a seminar at Tsinghua University, Beijing, 17 March 2000. The author would like to thank participants in the above workshops, conferences and seminar, J.R. Bhatt, A. Denny Ellerman, Prodipto Ghosh, Erik Haites, and Adam Rose for useful discussions and comments on an earlier version of the paper. The views expressed here are those of the author. The author bears sole responsibility for any errors and omissions that may remain. 


\section{References}

ADB (1998). Asian Least-Cost Greenhouse Gas Abatement Strategy: People's Republic of China. Manila: Asian Development Bank (ADB).

CASS (2000). China's Energy and Economy in the 21st Century. Unpublished Manuscript, Chinese Academy of Social Sciences (CASS), Beijing.

EIA (1999). International Energy Outlook 1999. Energy Information Administration (EIA), DOE/EIA0484(99), Washington, DC.

Ellerman, A.D., and A. Decaux (1998). Analysis of Post-Kyoto $\mathrm{CO}_{2}$ Emissions Trading Using Marginal Abatement Curves. MIT Joint Program on the Science and Policy of Global Change, Report No. 40, Massachusetts Institute of Technology.

IEA (1998). World Energy Outlook 1998. Paris: International Energy Agency (IEA).

MacCracken, C.N., Edmonds, J.A., S.H. Kim, and R.D. Sands (1999). The Economics of the Kyoto Protocol. Energy Journal 20 (Special Issue on the Cost of the Kyoto Protocol): 25-71.

McKibbin, W.J., Ross, M.T., Shackleton, R., and P.J. Wilcoxen (1999). Emissions Trading, Capital Flows and the Kyoto Protocol. Energy Journal 20 (Special Issue on the Cost of the Kyoto Protocol): 287-333.

UNFCCC (1997). Kyoto Protocol to the United Nations Framework Convention on Climate Change (UNFCCC). FCCC/CP/1997/L.7/Add.1, Bonn.

Van der Mensbrugghe, D. (1998). A (Preliminary) Analysis of the Kyoto Protocol: Using the OECD GREEN Model. Presented at the OECD Workshop on the Economic Modelling of Climate Change, 17-18 September, Paris.

World Bank (1994). China: Issues and Options in Greenhouse Gas Emissions Control. Report of a Joint Study Team from The National Environmental Protection Agency of China/The State Planning Commission of China/United Nations Development Programme/The World Bank. Washington, DC. Zhang, Z.X. (1997). The Economics of Energy Policy in China: Implications for Global Climate Change. New Horizons in Environmental Economics Series. England: Edward Elgar.

Zhang, Z X. (1998). Greenhouse Gas Emissions Trading and the World Trading Systems. Journal of World Trade 32 (5): 219-239. 
Zhang, Z.X. (1999). Estimating the Size of the Potential Market for All Three Flexibility Mechanisms under the Kyoto Protocol. Report Prepared for the Asian Development Bank under Contract TA-5592REG.

Zhang, Z.X. (2000). Estimating the size of the potential market for the Kyoto flexibility mechanisms. Weltwirtschaftliches Archiv - Review of World Economics 136 (3): 491-521. 